\title{
Study on Open Teaching Mode of Aeronautical Characteristic Architecture Specialized Courses
}

\author{
Ting Du \\ Binzhou University, Binzhou, Shandong, 256600
}

\begin{abstract}
Under the guidance of the goal of featuring aviation science and technology in Binzhou University, based on the resources of the school aviation specialty discipline, this paper explores the construction of buildings with the characteristics of aviation university through the teaching reform and development in the aspects of teaching, curriculum and teaching methods. Study professional courses, put forward the teaching concepts and methods of "building + aviation + structure" joint teaching, phased research type system, the composition of subject and object, and teaching classroom open and other teaching ideas and methods.
\end{abstract}

Keywords: Aviation characteristics; Research type system; Openness; Model research

DOI: $10.36012 /$ fhe.v1i1.568

$\mathrm{P}$ rofessional education in the senior stage of Architecture is an important link in undergraduate teaching of Architecture. It plays a crucial role in improving students' professional abilities and guiding future practice. Taking aviation science and technology as the school running characteristic, Binzhou University cultivates a large number of scarce talents for the current fast-growing air transport industry. The major of architecture relies on the resources of key disciplines of aviation in the school and seeks to build and perfect the teaching system of architecture design course with the characteristics of aviation. At the same time, the teaching process combined with the support of scientific research achievements and the scientific research into innovative teaching carrier to establish interdisciplinary and open teaching mode for the teaching of higher grade architecture in architecture, and to explore the teaching path and teaching methods for the training of innovative talents in interdisciplinary fields.

\section{Construction characteristics of architec- tural design course with aviation character- istics}

Aviation Architectural Design Course is the study of architectural design issues, in the field of construction and aviation cross-cutting areas. The content of the course is comprehensive, knowledge-linked and prospective. This requires students to: improve the structure of knowledge, establish a comprehensive cross-disciplinary way of thinking, use interdisciplinary research methods to solve the architectural design problems, and ultimately get the overall design and comprehensive quality improvement. Aeronautical architectural design course was set in the fourth grade, students at which stage mastered a certain degree of professional knowledge and comprehensive ability, with mature teaching conditions.

The course emphasizes the characteristics of students' knowledge structure and ability, consolidates the basis of consolidation, and focuses on the training of "using knowledge ability flexibly" and "communication and expression skills".

Design topics with aviation engineering practice, select the airport terminal and its ancillary facilities as the main teaching object. This type of building has a certain scale, strong functional complex, more comprehensive coverage of relevant knowledge points, with a certain degree of difficulty and challenge. Architectural design not only includes human behavior space, but also includes transport space such as aircraft, requiring students to design unfamiliar aviation related fields of expertise. Compared with the teaching content of the large public buildings in the original syl- 
labus, students need to solve many problems of more complicated diversified functions and streamlines and to create complex layered space forms. In summary, the curriculum needs to be more rigorous, more closely linked to the teaching plan.

\section{Construction links of aeronautical archi- tectural design course}

\subsection{Multidisciplinary joint teaching}

From the perspective of the development of education in architecture, the trend of comprehensive and diversified disciplines is widespread. The content of this course involves the interdisciplinary fields of urban and rural planning, aviation technology and structural engineering related to architectural design. The teaching process establishes a multidisciplinary joint teaching platform of "architecture + aviation + structure", sets up a team of teachers and introduces related pro-fessions teachers and design agency architects to conduct joint teaching. The key to joint teaching is to timely and appropriately establish the conversion rhythm of the teaching session, the mode of convergence and technical means of cross-teaching links in the teaching process.

(1) design program generation period

In the early stage of design, students were mainly asked to solve the problems of knowledge and design principle of aviation technology and aeronautical buildings. In addition to arranging basic knowledge lectures, architects of design institutes were invited to instruct students to conduct investigation and research on representative aeronautical buildings Shandong Province, Beijing and Tianjin, Aviation professional teachers involved in the teaching of the first draft of the first sketch, from a professional point of view about the principle and method of traffic flow organization, to guide students to correctly complete the building interior and outdoor plaza and the surrounding road traffic flow design.

(2) design program construction period

In the mid-design stage, the concept of the project has entered into the generation stage. The aviation construction conforms to the construction of space and long-span space, which is a difficult design issue for architecture students and also the teaching focus of this course. Students need to quickly master and be proficient in the use of structural and technical knowledge to establish the correct spatial logic. In this session, the structure of professional teachers will be introduced. First, the thematic form will strengthen the weak theoretical knowledge, to further analyze the concept of structure; Second, the construction and structure of the teacher will be one-on-one program of student guidance, combined with the student's physical model or computer model, counseling space construction and structural selection Design. Practical feedback, teaching effectiveness and efficiency have been greatly improved and students benefit greatly. (Figure 1: Disciplinary cross-class design assignment)
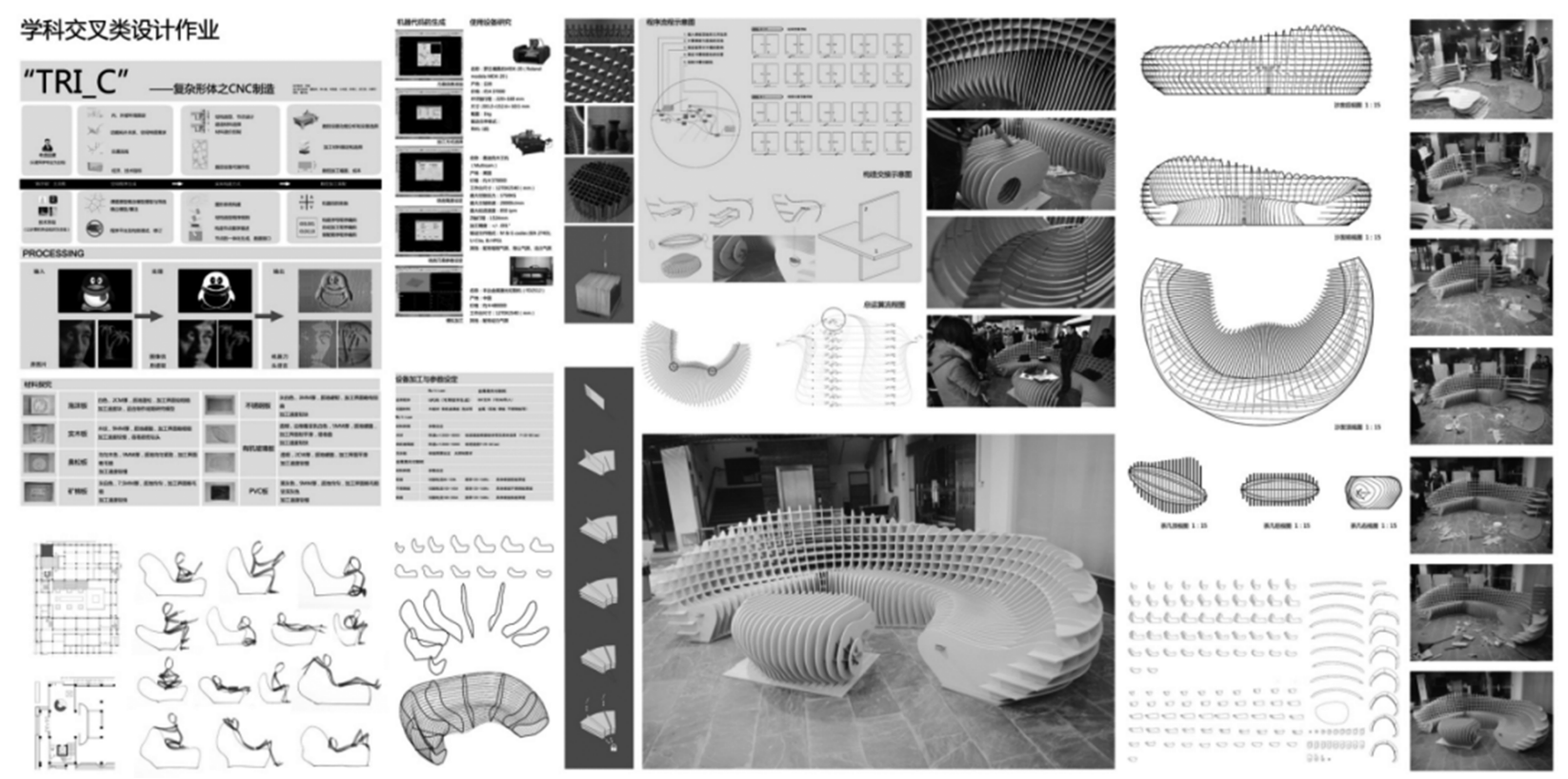

Figure 1 Disciplinary cross-class design assignment 
(3) design evaluation period

Post-evaluation of design is to improve students' ability to design an important part. In addition to centralized drawing, the course arranges for the students to walk into the design agency, communicate face to face with the masters, think about the differences between the feedback design and the actual project, and carry out "post-design" studies with problems. Through joint teaching with design institutes, a sustainable mechanism for evaluating extension and teaching of architecture design is effectively established.

\section{2 scientific research practice extending the re- search teaching}

Aeronautical building is an industrial and comprehensive building type, with outstanding design difficulties. The environmental conditions and cultural elements that affect the design are diverse, and the application of new technologies is also full of changes and challenges. Teaching focuses on stimulating students to explore the origin of the problem awareness, and to discover new problems, research and solve problems in active learning state. The research teaching mode of teaching people to catch fish is an important teaching method in the construction of this course so as to cultivate and improve the ability of senior students to integrate theory with practice and research innovation.

(1) the transformation of scientific research achievements into teaching carrier

The teachers' team has educational background of respective disciplines such as architecture, planning and technology. The teaching resources strive to have a sound knowledge structure and complement each other. First of all, by teaching combined with the teachers of scientific research topics and research results, the design of the task book will choose the actual project formulation, and amend the title based on teaching tasks, to develop a good mandate fully covering the current stage of teaching knowledge, introduction field of the latest scientific research results, and discussion
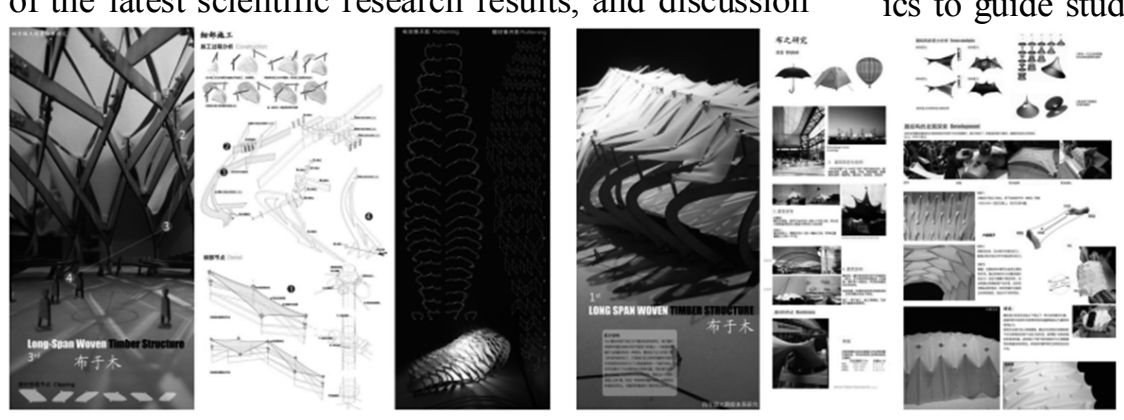

of the forefront in teaching with the students; Secondly, the teacher group conducts collaborative research at different stages and different scales according to the teaching content, course topics and teaching methods, who puts forward the teaching problems in the professional cross-cutting field, establishes the "combination point" of knowledge, and designs the teaching design so as to effectively master the teaching rhythm and teaching effect; Thirdly, some teachers are members of "aviation construction studio", for students who have more than left, instructed teachers to enter the studio to participate in research, encourage the cultivation of outstanding personnel.

(2) Improve the teaching of building technology

Construction technology is an important teaching content in the senior architectural design course, with ample knowledge and large amount of information. The teaching group directly introduces the practical aspects and walks out of the classroom together with the students for an intuitive on-site teaching. In practice teaching, we should not only interpret the engineering cognition in the mission statement but also strengthen the links in the construction of technology. Ask the engineering designers to give lectures on the theoretical knowledge and technical specifications such as the long-span structure, fire prevention and disaster prevention, equipment handling, etc. to obtain the participatory situation Learning experience. Through the implementation of teaching methods of practical research, students can quickly understand many obscure concepts, principles and correctly applied to the design, which improves teaching efficiency. (Figure two: architectural drawings and model training)

(3) "hard", "new" knowledge point method of research As mentioned earlier, "traffic organization, structure construction, laws and regulations" and other knowledge points for learning difficulties, the teaching process designed for these problems special research topics to guide students to carry out special studies. The-

Figure 2 architectural drawings and model training

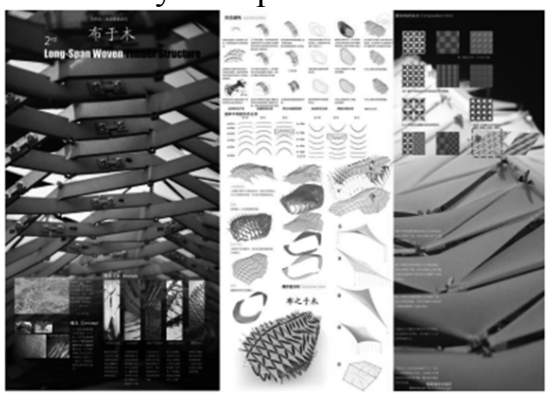


matic lectures are mainly arranged with such topics as "Principles and Technology of Aeronautical Architecture Design and Development Trends, Theory and Practice of Spatial Syntax Technology, Selection of Large-span Structures, Design Standards and Norms" and other lectures, for the purpose of addressing the teaching dif-ficulties, improving the knowledge structure, and guiding stu-dents to think from different perspectives to effectively improve students' comprehensive design ability.

\section{3 combined with the case of open teaching}

"Open" teaching is an effective way to expand students' comprehensive ability. The course starts with the teaching content and selects the design topics, based on the actual project cases, selecting the actual project address that is convenient for site visits, is a teaching process that is intuitive, specific and pertinent. It is essential to ensure the teaching effectiveness. The teaching process takes a multi-channel, multi-knowledge and multi-dimensional open teaching method, which breaks down the teaching activities of architectural design from the lecturing class and extends it from "outside the classroom". It will be a wide range of teaching methods added, with a variety of teaching methods, carrying teaching functions.

(1) engineering field teaching class

Make full use of the advantages of aviation construction case resources in Binzhou and Beijing-Tianjin regions, and organize student field trips to Jinan Yaoqiang Airport Terminal and Beijing T3 Terminal. Select Binzhou City and the surrounding cities within the scope of the project as a design site to determine the subject of the general layout of the curriculum design. This year, the site selection of Heze airport coincides with the open design bidding of the project, with appropriate size and taking the strategic cooperation agreement between our university and Heze airport as the platform, it has convenient teaching and learning environment.

(2) the design practice of production practice classroom

It cooperates with famous aeronautical and architectural design institutes both at home and abroad, such as Binzhou Planning and Design Institute and Beijing Design Institute, inviting leading architects to hold lec- tures and seminars, and establishing a practice teaching platform through various communication channels. Students and designers communicate face to face, directly interpret the works of designers, discuss the key issues in the creation of contemporary aviation architecture, and understand the cutting-edge information of engineering practice, so that the students' innovative awareness is greatly stimulated.

\section{Conclusion}

For teaching interdisciplinary courses, open teaching methods are positive. In the course of building aeronautical characteristic architecture courses, the author focuses on the practical problems encountered in multidisciplinary integration, breaks through the classroom teaching mode, extends from "inside the classroom" to "out of classroom", and carries out the diversified and open teaching reform. In the end, we will make use of the limited teaching time to grasp the teaching pace and take a positive and effective joint teaching platform to provide our students with a broader field of vision, basic skills and improve their design innovation ability.

\section{References}

[1] Li Baofeng. The evolution of the response - on the current architectural education a number of thinking $[\mathrm{J}]$. New Building .2017 (03): 50-51.

[2] Ding Wowo. Transition, transformation and construction [J]. New Building .2017 (03): 4-8.

[3] Wang Jianguo, Zhang Xiaochun. Contemporary Chinese architectural education trends and issues of thinking $[\mathrm{J}]$. Times Building .2017 (03): 6-9.

[4] Wu Liangyong. Generalized Architecture. Beijing: Tsinghua University Press, 1989.

[5] Deng Qingtan. Nursery Kindergarten building design said. Jinan: Shandong Science and Technology Press, 2006.

[6] Cai Chunmei. Childhood behavior observation and record. Shanghai: East China Normal University Press, 2013.

[7] Woo J H.BIM (Building Information Modeling) and Pedagogical Challenges [C]//Proceedings of the 43rd ASC National Annual Conference. 2006: 12-14

[8] Chuck Eastman, Paul Teicholz, Rafael Sachs, Kathleen Liston. BIM HANDBOOK A Guide to Building Information Modeling for Owners, Managers, Designers, Engineers, and Contractors [M]. Published by John Wiley\&Sons, Inc. Hoboken, New Jersey 2008: 116 